\title{
Booxter and LibraryThing Making cultural resource centers library collections visible and accessible
}

ike other academic libraries, Oregon State -University Libraries (OSUL) diligently reaches out to a wide variety of campus groups as part of its mission to develop user-focused services that contribute to student success..$^{1,2}$ Outreach to student groups focuses on equipping "students with tools and resources needed to succeed in and out of the classroom" and is intended to enhance their "evolving personal, social, emotional and academic endeavors" - all goals held in common with student service units. ${ }^{3}$

OSUL focuses some of its outreach efforts on The university's Cultural Resource Centers (CRCs) to meet these goals as well as embracing diversity as part of OSU's drive to excellence. ${ }^{4}$

Campus cultural centers have long supported ethnic minority students to adjust to and succeed at predominately White institutions (PWIs), higher education institutions with a $50 \%$ or greater White student body. ${ }^{5}$ Such institutions may carry a history of having been historically White prior to the outlawing of segregation and are differentiated from colleges and universities focused on ethnic minority students, such as historically Black colleges and universities. ${ }^{6}$

Ethnic minority students value cultural centers for widely varying reasons such as comfortable places to just "hang-out" to venues that bear the weight of cultivating a welcoming institutional climate at PWIs. ${ }^{7} \mathrm{~A}$ cultural center's campus presence demonstrates a "responsible and culturally sensitive position toward diversity, creating an environment that acknowledges, respects, and enhances multiculturalism." ${ }^{8}$ OSU's CRCs play similar roles on campus.

As the liaisons to OSU's CRCs our outreach efforts connected us to the director of the office of diversity development, who oversees them. The director asked for assistance with developing a common library system as a strategy to promote intra-center visibility. This is when OSUL's outreach efforts were called to go beyond typical instruction services. ${ }^{9}$ We describe a creative solution resulting in a library system for OSU's six CRCs: Asian \& Pacific Cultural Center (APCC); Centro Cultural César Chávez (CCCC); Lonnie B. Harris Black Cultural Center (BCC); Native American Longhouse Eena Haws (NAL); Pride Center (PC); and the Women's Center (WC).

\section{Discussion of need and development of solution}

In prior years, OSU's CRCs developed their own library collections ranging from approximately 400 to 1,800 books each, many of which were donated. The collections are accessible to anyone who visits the CRCs. Visitors are primarily students, some faculty and staff, and occasionally local commu-

Natalia Fernández is Oregon multicultural librarian e-mail: natalia.fernandez@oregonstate.edu, and Jane Nichols is digital humanities coordinator, social sciences and humanities librarian at Oregon State University, e-mail: jane.nichols@oregonstate.edu

(c) 2014 Natalia Fernández and Jane Nichols 
nity members. None of the libraries used a formal classification system, and there was no uniform circulation policy or system in place. Because adding the CRCs' collections to OSUL's system was not feasible, we had to develop a creative solution based on the center's needs. The director wanted an inventory management and circulation system that was low cost as well as easy to both use and administer. She also wanted a discovery system that allowed for all of the libraries donation of $\$ 25$. We set up an account and shared the username and password so it can be accessed online by all of the CRCs. The combination of Booxter and LibraryThing met the CRCs' needs.

\section{Project implementation}

Although the end goal was for the CRCs to have a system independent of the OSUL, as librarians, we were able to provide assistance in the system set up and staff training.

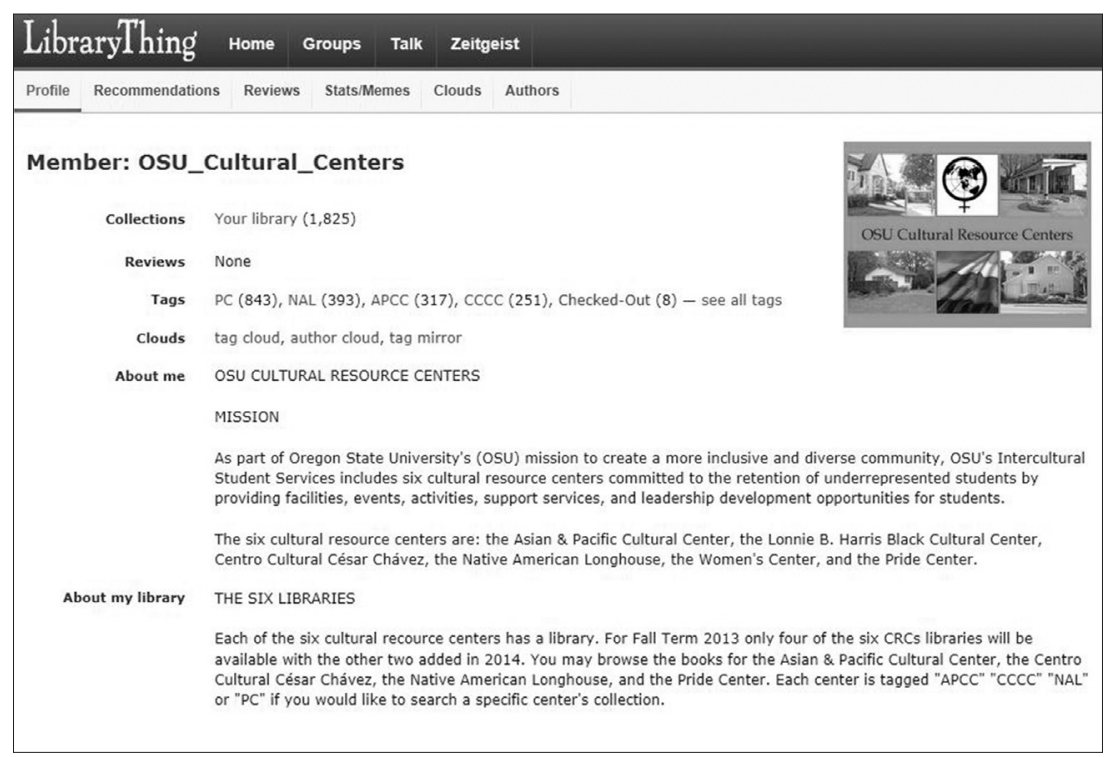

The CRCs' physical libraries are intellectually linked through a shared LibraryThing account at www.librarything.com/profile/OSU_Cultural_Centers. View this article online for more detailed images.

to be intellectually linked and accessible online, raising the collections' visibility to the OSU community.

After researching several options, we elected to use a combination of Booxter as an inventory management and circulation system and LibraryThing as the discovery tool. Booxter is an easy to use, inexpensive software for Macs. An individual account costs $\$ 30$. The software is similar to a personal ILS system; each book's record within a Booxter collection includes fields to track circulation.

LibraryThing is a free web-based software. It is donation-based, with an average
To begin, we met with the CRCs' student staff to explain the project goals and our expectations for their level of involvement. We organized the various elements of the project and then trained the students to implement the following eight steps:

1. Organize each library.

2. Set up a Booxter account for each center.

3. Input all book information into Booxter.

4. Set up a LibraryThing account.

5. Upload Booxter information into the LibraryThing account.

6. Develop circulation policies. 


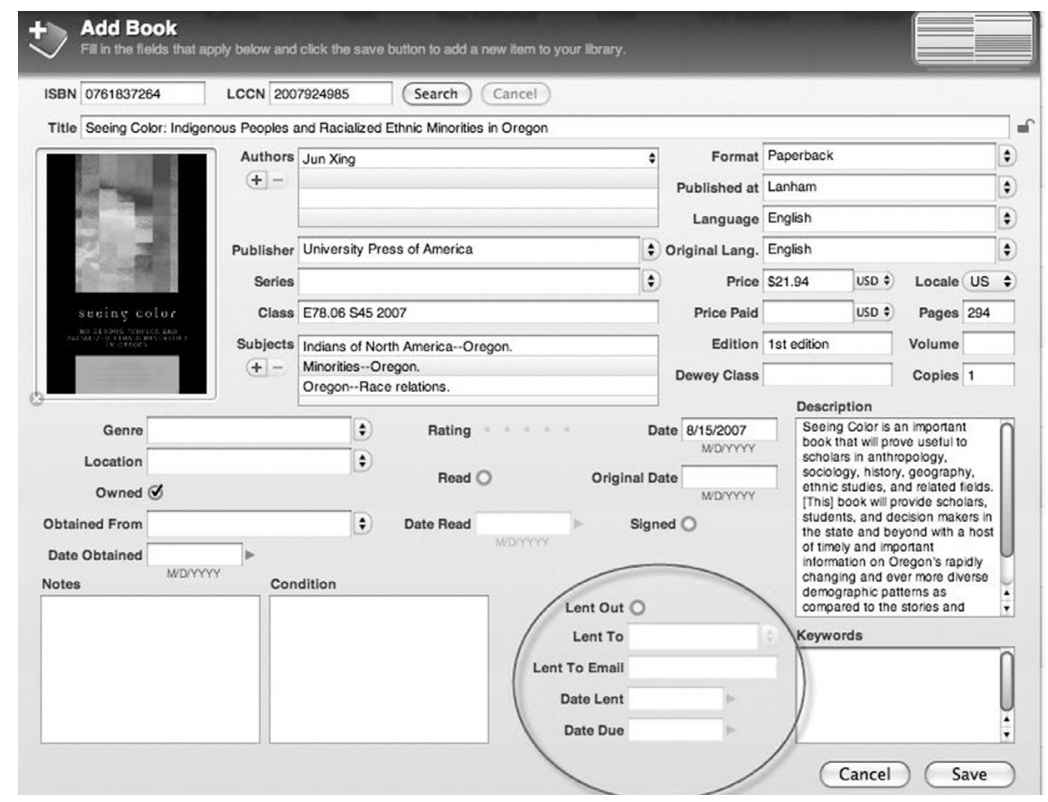

CSV file, which can then be uploaded into LibraryThing. LibraryThing uses a book's ISBN number to locate a book's publication information and jacket cover when available. If a book does not have an ISBN number, the book's information can be manually en-

Booxter is a program specifically designed for individuals to manage their personal tered. collections; each book's record includes fields to track its circulation.

We $\mathrm{met}$ with the CRCs

7. Create library manual.

8. Train all cultural center student staff.

The first step was to organize each of the libraries. Within each center a designated student or two worked to label each of the books with the center's contact information and Library of Congress call number. We trained the students to locate the call numbers and ISBN information and input it into Booxter. Next, the office of diversity development purchased four Booxter accounts and a student worker from the office set up an account for each center.

We practiced on a free version of the software to train ourselves and to create a set of instructions for the students to input each book's information into Booxter.

While the students worked on the Booxter portion of the project, we created a private LibraryThing account to test the system by uploading books, using various tags, and creating a profile. Once we established the workflow, we created a live account for the CRCs and then met with each center to upload the individual Booxter libraries. Booxter features the ability to export book data into a director to establish a basic set of circulation policies, including a check-out time of four weeks, renewals, holds, and the requirement of an OSU ID for check-out. We then created a library manual describing the library policies, the check-out and check-in instructions, and the steps on how to add a new book to the library. We met with each of the centers' staff to review the manual and train them to check-out/check-in books. The instructions were created so any staff member can check books in and out.

There are four check-out and check-in steps. The steps include using the check-out system in Booxter; physically labeling the book as checked-out on a small tag inserted in the back of the book; manually noting in LibraryThing that the book is checked-out; and, finally, sending a confirmation e-mail to the patron. To check-in a book, the same steps are repeated, but the check-out information is deleted. The steps take about five minutes to complete.

\section{Example check-out/check-in}

Step 1: Using the check-out/check-in system in Booxter 
We use the following Booxter fields: Lent Out, Lent To, Lent To E-mail, Date Lent, and Date Due. To keep track of additional information not accommodated by these fields, the Notes field is used to note whether a patron is a student, faculty, or staff member; the patron's phone number; and the name of the cultural center staff member who assisted the patron. To check-in a book, all of the patron's personal information is removed. In the notes field the check-out and check-in dates are kept along with the patron's status. These are kept for statistical purposes. No personal patron information is kept after a book is checked-in.

\section{Step 2: Physically labeling} a book as checked-out / checked-in

A small tag is pasted onto the inside back cover of each book. The tag features a table with the following columns: Due Date, Staff Initials, Checked-In Date, Staff Initials. With this tag the patron can easily check for the book's due date, and this tag can act as a physical record of a book's circulation history.

Step 3: Manually noting in LibraryThing that a book is checked-out/checked-in

LibraryThing is not set up to note whether or not a book is checked-out. Instead, we use the "tags" field to tag a book's status as "Checked-Out." Anyone searching the CRCs LibraryThing library can click on the tag to see what is checked-out. To check-in a book, the tag is simply deleted.

Step 4: Sending a confirmation e-mail to the patron

We created a Gmail account for all of the cultural centers to use. We also drafted emails for check-out, check-in, as well as for overdue books. CRC staff are required to use these templates by filling in the book and patron information. Once sent, a copy of the e-mail is moved into the appropriate "library" folder. Sent e-mails can assist with tracking usage.

\section{Lessons learned}

There were a few key lessons learned with this project. Most notably, the project took over two years to complete; however,

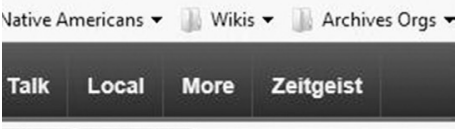

\begin{tabular}{|l|l|l|l|}
\hline E & क्षे \\
\hline
\end{tabular}

prev page I next page

Abbott, Sidney $1972 P C$
Feinberg, Leslie

An example of a "Checked-Out" tag for a Pride Center (PC) book.

Fulton, Jennifer $1992 \mathrm{PC}$
To designate the books within each library in the shared LibraryThing account, each cultural center is tagged by its common acronym, for example, the Pride Center is tagged "PC." And, to note if a book is checked-out, the tag "checked-out" is added to a book's record. depending on staffing, the project could conceivably be completed in about six months. Libraries interested in this solution can modify the timeframe to match their needs and those of the centers involved. Also, a project such as this likely only needs one librarian; we collaborated due to our distributed liaison model with the CRCs. CRCs student staff schedules and turnover extended the overall length of the project.

The students at each center have several duties keeping them occupied throughout the academic year. To work with their busy schedules, it was crucial to make sure they were on track and were completing the various project steps. Student turnover meant determining who the new contacts were and additional time spent to train new students. The other lesson learned was the tremendous benefit of having consistent administrative support for the project from the office with oversight over the CRCs. The director of the diversity development office was the main contact

(continues on page 335) 
Getting out into our campus community and attending diversity events and trainings led some students, staff, and faculty to feel more welcome in the library. Sharing our stories, supporting each other's work, fostering respect, and understanding are key to building cultural competency and a strong, just community.

\section{Notes}

1. D. Adkins and I. Espinal, "The Diversity Mandate," Library Journal 129 (April 2004): 7.
2. F. Brook, "Call for an Anti-Racist Approach in Librarianship," (June 3, 2013, web log post), retrieved from www.thebookaneers. com/2013/06/call-for-anti-racist-approach -in.html.

3. K. H. Hill, Diversity and multiculturalism in libraries (Greenwich, CT: JAI Press, 1994).

4. L. Mestre, Librarians serving diverse populations: Challenges and opportunities (Chicago: Association of College and Research Libraries, 2009).
("Booxter and ..." cont. from page 323)

person throughout the project. She was able to make over-arching decisions and organize staff trainings.

\section{Next steps and closing thoughts}

In fall term of 2013, we piloted the library circulation policies and procedures with the APCC, CCCC, NAL, and PC. We trained the center staff and asked them to market the existence and availability of the libraries so that the campus community could begin using the books with the new system. To further market the collections, each center will add the LibraryThing widget to their center's homepages, which will act as a direct link to the LibraryThing account for potential patrons to browse the collections.

The next steps are to determine if changes need to be made to the policies and procedures; address the need for an overdue policy; assess the circulation statistics; and schedule annual inventories. To complete the project, BCC and the Women's Center will be added within the next year. While the project research and implementation took about 80 hours, the maintenance of the system should be minimal.

A project such as this is applicable beyond cultural resource centers. Any group such as a student organization or department who wishes to make their library collections accessible could potentially use the Booxter/LibraryThing combination. This project offers a creative and innova- tive solution that enables OSU's CRCs to manage and promote their collections and allows OSU Libraries to extend its services and embed librarians throughout campus.

\section{Notes}

1. Emily Love and Margaret B. Edwards, "Forging inroads between libraries and academic, multicultural and student services," Reference Services Review 37, no. 1 (2009): 20-29, http://www.emeraldinsight.com /journals.htm?articleid $=1771179 \&$ show $=a b$ stract.

2. OSU Libraries and Press, OSU Libraries and Press Strategic Plan 2012-2017, http://osulibrary.oregonstate.edu/flipbook /strategicplan/.

3. Love, 21.

4. Oregon State University, OSU Strategic Plan, http://oregonstate.edu/leadership /strategicplan.

5. Encyclopedia of African American Education: Predominantly White Institutions, 2010, N-Z. doi: http://dx.doi. org/10.4135/9781412971966.n193.

6. Ibid.

7. Lee Jones, Jeanett Castellanos, and Darnell Cole, "Examining the Ethnic Minority Student Experience at Predominantly White Institutions: A Case Study," Journal of Hispanic Higher Education 1, no. 1 (2002): 1939, http://jhh.sagepub.com/content/1/1/19. abstract.

8. Ibid.

9. Love, 21. n 